\title{
Patterns of Rheumatic Heart Disease and Treatment Practices at Tertiary Care Center in Nepal: A Descriptive Cross-sectional Study
}

\author{
Rajesh Nepal, 'Madhab Bista, 'Sahadeb Prasad Dhungana' \\ 'Department of Internal Medicine and Cardiology Unit, Nobel Medical College Teaching Hospital, Biratnagar, Nepal.
}

\begin{abstract}
Introduction: Rheumatic heart disease is a sequel of rheumatic fever which causes heart valve damage. This study was conducted to look at the pattern of valve lesions and treatment practices in patients with rheumatic heart disease.
\end{abstract}

Methods: A cross-sectional study conducted at the tertiary care center with a diagnosis of rheumatic heart disease from July 2018 to January 2020 by convenient sampling. Ethical clearance was obtained from the Institutional Review Committee (ref no. 55/2018). Data were analyzed by using Statistical package for social sciences version 20 .

Results: Out of 600 patients, $428(71.3 \%)$ were female. The mean age was $44.24 \pm 14.24$ years. The isolated mitral valve was affected in 280 (46.6\%). Dual involvement of mitral and aortic valve was present in 294 (49\%). Only 14 (2.3\%) had involvement of isolated aortic valve involvement. Overall, mitral stenosis was the most common abnormality 508 (84.6\%) followed by mitral regurgitation 418 (69.6\%), aortic regurgitation 320 (53.3\%), and aortic stenosis 63 (10.5\%). Assessment of the severity of lesions showed that $247(41.2 \%)$ patients had severe mitral stenosis, $119(19.8 \%)$ severe mitral regurgitation, $14(2.3 \%)$ severe aortic stenosis, and 11 (1.8\%) severe aortic regurgitation. Majority 493 $(82.2 \%)$ were treated with medical therapies. Surgical procedures were performed in $51(8.5 \%)$. The use of anticoagulation was in $212(35.3 \%)$ of eligible patients.

Conclusions: Mitral valve was affected commonly both in isolation and combination. The majority of patients who were eligible for cardiac interventions were treated medically with suboptimal use of anticoagulation and secondary prophylaxis.

Keywords: rheumatic heart disease; spectrum analysis; treatment.

\section{INTRODUCTION}

Rheumatic heart disease (RHD) is an important preventable cause of cardiovascular disability and mortality in developing countries. According to world health organization (WHO), at least 15.6 million people worldwide have RHD. ${ }^{1}$ Of the 5,00,000 individuals who acquire acute rheumatic fever (ARF) every year, $3,00,000$ go on to develop RHD and 233,000 deaths annually are attributed to ARF or RHD. ${ }^{1}$

Various studies have been published on the prevalence of RHD in Nepal in various journals. ${ }^{2-5}$ All these studies showed the prevalence of RHD among school children to be between 0.9-1.35 per thousand in different parts of Nepal. Single or combined valvular lesions are present with variable clinical presentations in RHD patients. There are limited data on the clinical spectrum of RHD and treatment practices from our population.

Correspondence: Dr. Rajesh Nepal, Department of Internal Medicine and Cardiology Unit, Nobel Medical College Teaching Hospital, Biratnagar, Nepal. Email: rajesh328@hotmail.com, Phone: +977-9851072735. 
Nepal et al. Patterns of Rheumatic Heart Disease and Treatment Practices at Tertiary Care Centre in Nepal: A Descriptive..

Therefore, this study was conducted to look at the pattern of valvular lesions and to find out treatment practices in RHD patients at tertiary care hospitals in the eastern part of Nepal.

\section{METHODS}

This is a descriptive cross-sectional study conducted at Nobel Medical College Teaching Hospital who were at an outpatient or admitted at the cardiology unit from July 2018 to January 2020 after getting approval from the Institutional review committee (ref no. 55/2018). Six hundred patients (more than calculated sample size of 338 ) of RHD with age $\geq 12$ years were included in the study. Patients with degenerative valvular disease and children with acute rheumatic fever below 12 years of age were excluded from the study. All the participants had signed the consent for the study. The diagnosis of RHD was made based on clinical history, examination, and echocardiogram. Electrocardiography and echocardiography were performed in each individual.

The minimum sample size of 338 was calculated based on the $33 \%$ hospital prevalence of RHD (around onethird of total admission in cardiology unit - educated guess).

$$
\begin{aligned}
\mathrm{n} & =\mathrm{Z}^{2} \times \mathrm{p} \times \mathrm{q} / \mathrm{e}^{2} \\
& =(1.96)^{2} \times 0.33 \times 0.67 /(0.05)^{2} \\
& =3.84 \times 0.22 / 0.0025 \\
& =338
\end{aligned}
$$

where,

$\mathrm{n}=$ required sample size

$Z=1.96$ at $95 \%$ confidence interval

$\mathrm{p}=$ hospital prevalence of cardiac unit $(33 \%$ -

educated guess)

$q=1-p$

$e=$ margin of error, $5 \%$

Data were collected with the inclusion of pre-specified clinical parameters in Performa by convenient sampling method. The data were collected and entered in MSExcel 2007 and analyzed using the Statistical package for social sciences (SPSS) version 20 software. For descriptive statistics percentage, mean and standard deviation were calculated. The graphical and tabular presentation was made for appropriate variables.

All RHD patients underwent mode (M), 2-dimensional (2D), color flow and pulsed wave Doppler transthoracic echocardiography by Siemens echo machine. Echocardiograms were obtained at rest in the left lateral decubitus or supine position using standard parasternal and apical views. All the measurements were made by the leading-edge and averaged over three cardiac cycles.

\section{RESULTS}

Out of a total of 600 patients who were included in the study, 428 (71.3\%) were female and $172(27.6 \%)$ were male. The mean age was $44.24 \pm 14.24$ (range

\begin{tabular}{|c|c|}
\hline Characteristics & n (\%) \\
\hline Male & $172(27.6)$ \\
\hline Female & $428(71.3)$ \\
\hline Smoker & $106(17.6)$ \\
\hline Alcohol use & $66(11)$ \\
\hline History of rheumatic fever & $12(2)$ \\
\hline Characteristics & Mean \pm SD \\
\hline Mean age in years (Total) & $44.24 \pm 14.24$ \\
\hline Male & $43.33 \pm 13.74$ \\
\hline Female & $44.61 \pm 14.43$ \\
\hline Mean ${ }^{*} \mathrm{BMI}$ & $21.5 \pm 4.62$ \\
\hline Waist: hip ratio & $0.85 \pm 0.08$ \\
\hline Mean systolic blood pressure & $112.6 \pm 16.1$ \\
\hline Mean diastolic blood pressure & $73.4 \pm 10.4$ \\
\hline Mean blood pressure & $86.4 \pm 11.04$ \\
\hline Mean heart rate, †BPM & $87.6 \pm 18.7$ \\
\hline Creatinine & $0.9 \pm 0.15$ \\
\hline eGFR & $77.1 \pm 25.2$ \\
\hline Mean hemoglobin, gm/dl & $12.3 \pm 1.8$ \\
\hline Mean **TLC & $7693 \pm 3826$ \\
\hline Mean Platelets & $234.6 \times 10^{3} \pm 55.03$ \\
\hline Mean $++\mathrm{CHA}_{2} \mathrm{DS}_{2}$ VaSC score & $0.98 \pm 0.81$ \\
\hline
\end{tabular}
$8-83)$ years. The majority of the RHD patients belonged to $31-50$ years $(51.6 \%)$. The baseline characteristics of patients with RHD are shown below (Table 1).

*BMI: body mass index; $† B P M$ : beat per minute; $\square \square$ eGFR: estimated glomerular filtration rate; ${ }^{* *}$ TLC: total leucocyte count; $++\mathrm{CHA}_{2} \mathrm{DS}_{2}$ VaSC: chronic heart failure, age, hypertension, diabetes mellitus, stroke, vascular disease, sex category.

The distribution of patients with RHD according to different age groups is shown below (Figure 1). 
Nepal et al. Patterns of Rheumatic Heart Disease and Treatment Practices at Tertiary Care Centre in Nepal: A Descriptive..

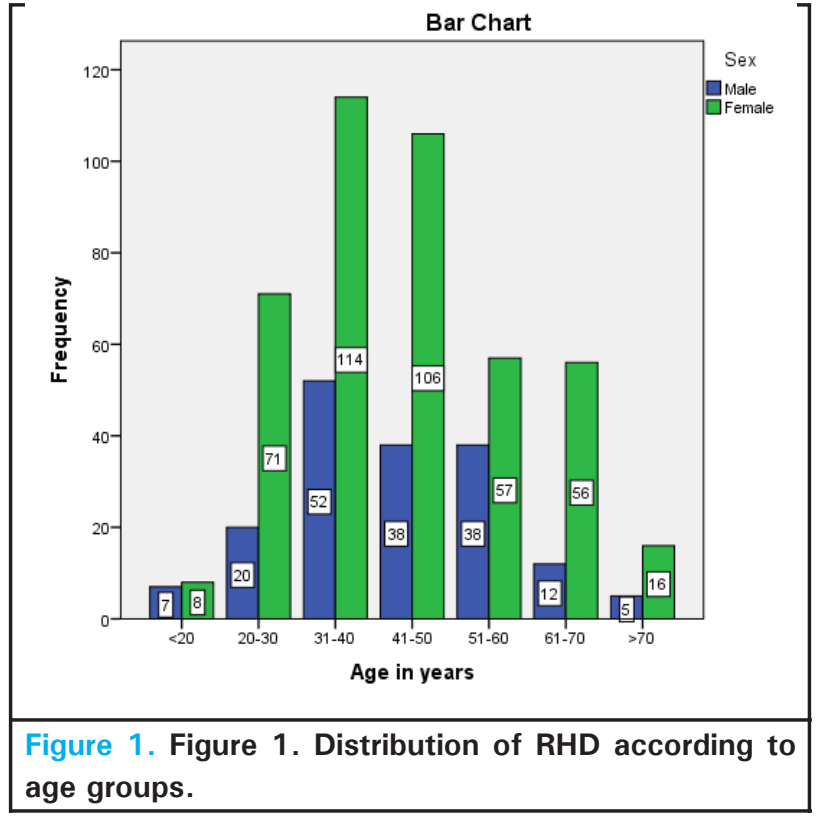

Isolated mitral valve $280(46.6 \%)$ was the most commonly affected valve in our study. Dual involvement of mitral and aortic valve was present in 294 (49\%). Only $14(2.3 \%)$ had involvement of isolated aortic valve and $12(2 \%)$ had involvement of combined mitral, aortic, and tricuspid valves and none had pulmonary valve involvement as shown in (Figure 2).

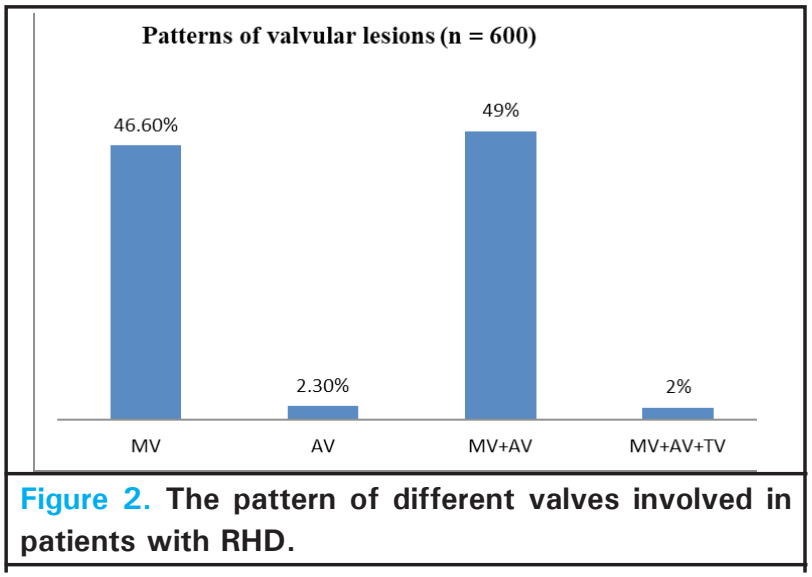

Among patients who had either isolated or combined valvular lesions, MS was the most common abnormality 508 (84.6\%) followed by MR 418 (69.6\%), AR 320 (53.3\%), and AS $63(10.5 \%)$. There was overlapping of the stenotic and regurgitant lesions of different severity in a single valve or combined lesions. TR was present in the majority of patients 590 (98.3\%) including both organic valvular involvement $12(2 \%)$ and functional $578(96.3 \%)$. Assessment of the severity of various valvular lesions showed that 247 (41.2\%) patients had severe MS, $119(19.8 \%)$ patients had severe MR, $14(2.3 \%)$ patients had severe AS and $11(1.8 \%)$ had severe AR. The severity of valvular lesions is illustrated below in (Table 2).

Table 2. The severity of valvular lesions in patients with RHD.

\begin{tabular}{|lllll|}
\hline Valve lesions & Total $\mathbf{n}(\%)$ & Mild $\mathbf{n}(\%)$ & Moderate $\mathbf{n}(\%)$ & Severe $\mathbf{n}(\%)$ \\
* MS & $508(84.6)$ & $113(18.8)$ & $148(24.6)$ & $247(41.2)$ \\
†MR & $418(69.6)$ & $182(30.3)$ & $117(19.5)$ & $119(19.8)$ \\
IAR & $320(53.3)$ & $246(41)$ & $63(10.5)$ & $11(1.8)$ \\
${ }^{*}$ AS & $63(10.5)$ & $18(3)$ & $31(5.2)$ & $14(2.3)$ \\
††TR & $590(98.3)$ & - & - & - \\
Organic & $12(2)$ & - & $186(32.1)$ & $12(100)$ \\
Functional & $578(96.3)$ & $212(36.6)$ & $(31.1)$ \\
\hline
\end{tabular}

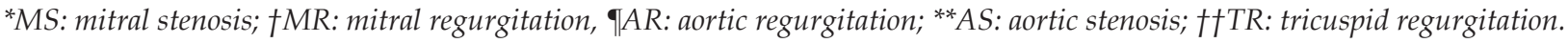

Overall, 150 (25\%) patients had tachycardia (heart rate $>100 /$ minute), prevalence of AF was 220 (36.6\%). The majority of patients $(89.6 \%)$ had enlarged left atrium (>40 mm). Reduced left ventricular systolic function was noted in $473(78.8 \%)$, pulmonary artery hypertension in $260(41.6 \%)$, left atrial clot in 30 (9.1\%) patients.

The majority of patients $493(82.2 \%)$ were being treated with various medical therapies. History of prior PTMC was noted in $56(9.3 \%)$ of patients. Different Surgical procedures were performed in $51(8.5 \%)$ of patients as shown in (Table 3 ). The use of anticoagulation therapy was documented in 212 (35.3\%) of high-risk eligible patients. Only 174 (29\%) of the study population was receiving secondary prophylaxis.

\begin{tabular}{|lc|}
\hline \multicolumn{2}{|l|}{ Table 3. Current treatment of patients with RHD. } \\
\hline Treatment & $\mathbf{n}(\%)$ \\
Medical treatment & $493(82.2)$ \\
Beta-blockers & $355(59.2)$ \\
Digoxin & $119(19.8)$ \\
Calcium channel blockers & $37(6.2)$ \\
Anticoagulation (Warfarin) & $212(35.3)$ \\
Secondary prophylaxis & $174(29)$ \\
*PTMC & $56(9.3)$
\end{tabular}


Nepal et al. Patterns of Rheumatic Heart Disease and Treatment Practices at Tertiary Care Centre in Nepal: A Descriptive..

\begin{tabular}{|ll|} 
†MVR & $35(5.8)$ \\
IDVR & $7(1.2)$ \\
$*{ }^{*} \mathrm{CMC}$ & $6(1)$ \\
††AVR & $3(0.5)$ \\
\hline
\end{tabular}

*PTMC: percutaneous transluminal mitral commissurotomy; †MVR: mitral valve replacement; IDVR: double valve replacement; **CMC: closed mitral commissurotomy; ††AVR: aortic valve replacement.

\section{DISCUSSION}

This is a hospital-based study providing data on clinical patterns of RHD concerning age and gender distribution, the pattern of valves involvement, and treatment practices in the eastern region of Nepal. Similar to other studies performed in Nepal, our study revealed that RHD was more common among patients of the age group between 20 to 50 years accounting for around two-thirds of total cases. A study conducted by Koirala PC, et al. ${ }^{6}$ in National Heart Center showed that RHD was more common among patients of age group 10-40 years with a female predominance. Similarly, studies done by Laudari S, et al. ${ }^{7}$ and Kafle, et al. ${ }^{8}$ in different regions of Nepal showed that the majority of the patients belonged to productive age of life with a common age group being in between 21 to 40 years. In our study, females were more commonly involved than males with female to male ratio of 2.4 . That could be probably due to lack of access to health care and proper treatment of sore throat in female children because of gender biases or other factors that still prevails in our Nepalese community.

In our study, mitral valve was affected in the majority of patients $(95.6 \%)$ followed by an aortic valve $(51.3 \%)$ similar to study done in National Heart Center ${ }^{6}$ that showed that mitral valve was the most commonly affected valve $(98.20 \%)$ followed by the aortic valve $(53.90 \%)$. Overall, mitral stenosis was the predominant lesion (84.6\%) followed by mitral regurgitation (69.6\%). Prevalence of predominant MS was found to be more in our study than in a large retrospective analysis in south India that showed predominant MS was present in $41.5 \%$ of the population age for more than 18 years. In our study, an isolated mitral valve was the most commonly involved valve $(46.60 \%)$ followed by an isolated aortic valve $(2.30 \%)$ similar to other studies conducted in other parts of Nepal. ${ }^{6,7}$ Laudari S, et al. ${ }^{7}$ showed that an isolated mitral valve was the most commonly involved valve $(46.80 \%)$ followed by an isolated aortic valve $(9.36 \%)$. Similarly, Koirala PC, et al. ${ }^{6}$ revealed that the isolated mitral valve was far more $(46.05 \%)$ than the isolated aortic valve $(1.9 \%)$.

Concerning isolated aortic valve disease, our study showed a similar prevalence $(2.3 \%)$ like the study done in south India (2.8\%). Multi valvular involvement (mitral plus aortic valve) was present in $49 \%$ of patients in this study similar to a study done by Laudari, et al. ${ }^{7}$ in other parts of Nepal which showed that combined mitral plus aortic valve lesions were the most common. This is also similar to the study done in India where commonest valvular lesions were combined MS and MR (42.9\%). ${ }^{10}$ Treatment decision of patients with RHD is made based on the clinical status, the severity of valve lesions, and resources available at the center providing the care. Surgical treatment is indicated if the patient is symptomatic or LV dysfunction is present. Few tertiary care centers outside the Kathmandu valley regularly perform valvotomies and valve surgeries in clinically indicated patients. The majority of patients are treated medically even if indicated for valvotomies or surgical intervention due to various reasons like financial constraints, lack of manpower or resources, limited knowledge, advanced disease at presentation with high peri-procedural complications, etc. In our study, the majority were treated with medical therapy $(82.2 \%)$ with the rest had undergone some type of cardiac interventions in the past. Percutaneous transluminal mitral valvoplasty (PTMC) is performed if the valve anatomy is favorable and there is no significant MR. ${ }^{11}$ Around $10 \%$ of our patients had undergone PTMC with favorable anatomy before enrollment. In our study, out of 220 patients of MS with AF, only $35.3 \%$ patients were on warfarin (DOACs rarely used in our settings) at the time of enrollment as seen in the study done in the rural part of Nepal where only $22.7 \%$ patients with RHD and AF were on oral anticoagulants ${ }^{12}$ that underscores the marked underuse of anticoagulation in clinically indicated patients.

The previous study ${ }^{13}$ suggests that a history of rheumatic fever (RF) is missed in almost more than 50 percent of patients with RHD. Interestingly, only 2 percent of our patients could recall the childhood manifestations of RF suggesting that our population has a higher prevalence of subclinical carditis. Secondary prophylaxis is indicated in RHD patients who had either history of RF or documented RHD. Three weekly intramuscular injections of benzathine benzylpenicillin are indicated as the most effective therapy for secondary prevention. ${ }^{1}$ Only $29 \%$ of our patients were prescribed penicillin therapy that too oral penicillin due to factors like fear of anaphylaxis, poor access to health care facility every three weeks, etc.

The main limitation of the study is that this is a hospitalbased cross-sectional study and provides information related to patients referred to a tertiary care hospital. Hence these results may not be generalized to the general population because of referral bias. 
Nepal et al. Patterns of Rheumatic Heart Disease and Treatment Practices at Tertiary Care Centre in Nepal: A Descriptive..

\section{CONCLUSIONS}

RHD is still a major problem in Nepal. It is important to be familiar with patterns and severity of valvular lesions and treatment modalities provided to improve the care of such patients in our settings. MV was most commonly affected both in isolation and combination. The majority of patients who are eligible for cardiac interventions are treated medically with suboptimal use of anticoagulation and secondary prophylaxis. This demands to look at the reasons behind not giving treatment as par with the evidence-based guidelines and address the obstacles related to it. Improved knowledge of treatment based on the severity of disease in addition to primary and secondary prevention helps to reduce the burden of RHD.

\section{Conflict of interest: None}

\section{REFERENCES}

1. The current evidence of the burden of Group A streptococcal diseases. Geneva, Switzerland: World Health Organisation; 2004 [cited 2020 June 22]. 57 p. Available from: https:/ /apps. who.int/iris/bitstream/handle/10665/69063/WHO_FCH_ CAH_05.07.pdf. [피ll Text]

2. Shrestha NR, Karki P, Mahto R, Gurung K, Pandey N, Agrawal K, et al. Prevalence of subclinical rheumatic heart disease in eastern Nepal: a school-based cross-sectional study. JAMA Cardiol. 2016;1(1):89-96. [PubMed | Full Text | $\underline{\mathrm{DOI}}]$

3. Regmi PR, Shakya U, Adhikaree A, Paudyal. Rheumatic heart disease in school going children: a cross-sectional epidemiological profile of Jajarkot, Nepal. Nepalese Heart Journal. 2019;16(2):1-4. [Full Text | DOI]

4. Man Bahadur KC. Rheumatic heart disease in Nepal: current scenario. Nepalese Heart Journal. 2016;13(2):1-2. [Full Text | $\underline{\mathrm{DOI}}]$

5. Prajapati D, Sharma D, Regmi P, Khanal H, Baidya S, Rajbhandari S, et al. Epidemiological survey of rheumatic fever, rheumatic heart disease and congenital heart disease among school children in Kathmandu valley of Nepal. Nepalese Heart Journal 2014;10(1):1-5. [․ㅏll Text | DOI]

6. Koirala PC, Sah RK, Sharma D. Pattern of rheumatic heart disease in patients admitted at tertiary care centre of Nepal. Nepalese Heart Journal. 2018;15(1):29-33. [Full Text | DOI]

7. Laudari S, Subramanyam G. A study of spectrum of rheumatic heart disease in a tertiary care hospital in central Nepal. Int J Cardiol Heart Vasc. 2017 Apr 21;15:26-30. [PubMed | Full Text | DOI]
8. Kafle RC, Alurkar VM, Paudel N, Jha GS. Pattern of valvular involvement in rheumatic heart disease patients in a tertiary care hospital of western Nepal. Nepalese Heart Journal 2016;13(2):29-31. [Full Text | DOI]

9. Chockalingam A, Gnanavelu G, Elangovan S, Chockalingam V. Clinical spectrum of chronic rheumatic heart disease in India. I Heart Valve Dis. 2003 Sep;12(5):577-81. [uuMed | Full Text]

10. Joseph N, Madi D, Kumar GS, Nelliyanil M, Saralaya V, Rai S. Clinical spectrum of rheumatic fever and rheumatic heart disease: a 10 year experience in an urban area of south India. N Am J Med Sci. 2013 Nov;5(11):647-52. [라Med | Full Text I DOI]

11. Nishimura RA, Otto CM, Bonow RO, Carabello BA, Erwin JP, Guyton RA, et al. 2014 AHA/ACC guideline for the management of patients with valvular heart disease: executive summary: a report of the American college of cardiology/American heart association task force on practice guidelines. Circulation. 2014 Jun;129(23):2440-92. [PubMed |

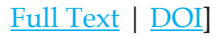

12. Dhungana SP, Sherpa K. Antithrombotic agents, and risk profile of patients with atrial fibrillation from rural part of nepal. Journal of Institute of Medicine. 2015;37(2):16-21. [․ㅏll] Text]

13. Kumar RK, Tandon R. Rheumatic fever \& rheumatic heart disease: the last 50 years. Indian J Med Res. 2013 Apr;137(4):643-58. [uued | Full Text]

The Author(s) 2018.

This work is licensed under a Creative Commons Attribution 4.0 International License. The images or other third party material in this article are included in the article's Creative Commons license, unless indicated otherwise in the credit line; if the material is not included under the Creative Commons license, users will need to obtain permission from the license holder to reproduce the material. To view a copy of this license, visit http://creativecommons.org/licenses/by/4.0/ 